\title{
EDITORIAL \\ Perceive the differences, differentiate the perceptions: why should we be interested in TBI management in Tanzania?
}

\author{
Franco Servadei, MD, Riccardo Spaggiari, MD, and Maria Pia Tropeano, MD \\ Department of Neurosurgery, Humanitas University and Research Hospital, Milan, Italy
}

$\mathrm{T}$ HE year 2015 was a turning point for surgery with the collective realization of surgery as a global health priority. The Lancet Commission on Global Surgery highlighted the disparities in surgical care worldwide and identified surgery as an "indivisible and indispensable part of health care," with-in addition-important social and economic consequences. ${ }^{10}$ Until that commission report, worldwide resources devoted to healthcare in developing countries were concentrated on infectious diseases (clean water, sanitation, antibiotics, vaccines, HIV, etc.). Global surgery was defined as the "area of study, research, practice and advocacy that seeks to improve health outcomes and achieve health equity for all people in the world who need surgical and anesthesia care." 10

We, as neurosurgeons, are an important part of this process, as reported by Park:"1 "Global Neurosurgery" became a movement emulated by other surgical specialties. ${ }^{16}$ In low- and middle-income countries (LMICs), neurosurgery displays several discrepancies compared with highincome countries (HICs). First (from a quantitative point of view), of the 49,940 neurosurgeons operating around the world, only a minority (less than $20 \%$-approximately 7000 ) are operating in LMICs, where almost $46 \%$ of the global population resides. ${ }^{13}$ Furthermore, these practitioners are operating in poor-resource settings where basic equipment is not always available.

Apart from numbers, differences in terms of epidemiology, patient management, and provision of care are also evident. These differences are particularly clear when we consider the most important neurosurgical disease in LMICs: traumatic brain injury (TBI), ${ }^{4,5}$ The typical patient suffering from craniocerebral trauma in LMICs is a young working adult, usually male, involved in a road traffic collision-in contrast to the typical patient with TBI in an $\mathrm{HIC}$, an elderly patient (usually undergoing antiplatelet or antiaggregant therapy) falling at home. ${ }^{9}$ In these scenarios even traumatic hematomas are different, with more acute epidural and subdural hematomas in LMICs and more contusions and chronic subdural hematomas in HICs.

Because effective interventions are not possible without data, how many papers dealing with neurotrauma are published from LMICs? A recent review showed a reverse correlation between incidence of TBI and related publications all around the world (Tropeano et al., unpublished data). This is most evident in LMICs, where published peer-reviewed papers on TBI are extremely limited, with a publication rate of only $11.08 \%$ of all LMIC neurosurgical publications..$^{14}$ A direct consequence of the lack of quality papers from LMICs is the absence of consideration for these countries when we produce evidence-based guidelines. ${ }^{2}$ A different process like a consensus conference can include experts from these countries, but the lack of papers remains a major obstacle.

In this scenario, Elahi et al. provide an interesting overview of TBI at a tertiary referral center in Tanzania. ${ }^{6}$ Because the current neurosurgical workforce does not address the neurotrauma demand in many African countries, the neurosurgical procedures were performed by general surgery attendings and residents. The authors observed a benefit of surgery for all TBI severities, with the greatest improvement in outcome for moderate TBI, followed by mild and severe TBI. The positive impact of surgery on patient outcome was also highlighted recently for traumatic spine injury in the same area. ${ }^{8}$ Both papers are the result of long-lasting collaborations between American universities (Duke University and Cornell University) and different African institutions in Tanzania. ${ }^{6,8}$

Even if there are other experiences for improving the number and quality of neurosurgeons in countries with limited resources, $, 2,13$ the so-called "twin collaboration" between American and African institutions seems to be effective. In the paper from Elahi et al. ${ }^{6}$ there are robust advanced statistics to reinforce the results found-even if it is common knowledge that the indications for surgery 
and the outcomes of patients with TBI are so complex that no statistical analysis alone can support them.

But this is not the most important part of this paper. We have 4 important messages from this study:

1) Time to surgery in the African (or LMIC) context does not influence outcomes, at least within 24 hours. ${ }^{6}$ A recent paper from Cambodia demonstrated that the Western "golden hour" is in reality 4 hours in the Cambodian environment. ${ }^{1}$ Surgery for TBI is important even if according to our Western standard it is performed late.

2) Where neurosurgeons are not available, general surgeons with limited neurosurgical training can take care of patients with TBI. In some countries like Malaysia, there is a full training program for general surgeons operating in remote areas. ${ }^{15}$ In Africa there are strong concerns about the training of general surgeons to perform surgery for TBI, but we believe that publishing data from the local LMIC experience will contribute to the ongoing discussion. ${ }^{17}$

3) The most benefit from surgery was for patients with moderate TBI. ${ }^{6}$ It is not surprising that in countries with limited resources, patients with severe TBI are difficult to treat. They require (apart from surgery itself) ventilation, ICU beds, post-acute care, and intensive rehabilitation. Patients with moderate TBI have a high risk of surgical complications but can often be treated with much fewer resources; therefore a priority treatment for these patients seems reasonable. ${ }^{3}$

4) GOS score follow-up at 6-12 months after injury in an LMIC context is unrealistic and only the outcome at discharge can be calculated.

We need to consider TBI as a worldwide occurrence and try to find a "cure" that can be applied where most of the trauma is now occurring-in LMICs. Knowledge of the epidemiology and optimal management in these countries is the basis for any action to improve outcomes.

Science can advance only with data and numbers: as Galileo Galilei said, "Measure what is measurable, and make measurable what is not so." In our opinion the neurotrauma research community has the duty to help the major portion of our world-LMICs - to render measurable the epidemiology and management of TBI in order to improve the outcomes of all our patients.

https://thejns.org/doi/abs/10.3171/2019.8.FOCUS19682

\section{References}

1. Barthélemy EJ, Spaggiari R, Corley J, Lepard JR, Staffa SJ, Iv V, et al: Injury-to-admission delay beyond 4 hours is associated with worsening outcomes for traumatic brain injury in Cambodia. World Neurosurg 126:e232-e240, 2019

2. Carney N, Totten AM, O'Reilly C, Ullman JS, Hawryluk GWJ, Bell MJ, et al: Guidelines for the Management of Severe Traumatic Brain Injury, Fourth Edition. Neurosurgery 80:6-15, 2017

3. Compagnone C, d'Avella D, Servadei F, Angileri FF, Brambilla G, Conti C, et al: Patients with moderate head injury: a prospective multicenter study of 315 patients. Neurosurgery 64:690-696, 2009

4. Dewan MC, Rattani A, Fieggen G, Arraez MA, Servadei F, Boop FA, et al: Global neurosurgery: the current capacity and deficit in the provision of essential neurosurgical care. Executive Summary of the Global Neurosurgery Initiative at the Program in Global Surgery and Social Change. J Neurosurg 130:1055-1064, 2019

5. Dewan MC, Rattani A, Gupta S, Baticulon RE, Hung YC, Punchak M, et al: Estimating the global incidence of traumatic brain injury. J Neurosurg 130:1080-1097, 2019

6. Elahi C, Rocha TAH, da Silva NC, Sakita FM, Ndebea AS, Fuller A, et al: An evaluation of outcomes in patients with traumatic brain injury at a referral hospital in Tanzania: evidence from a survival analysis. Neurosurg Focus 47(5):E6, 2019

7. Hutchinson PJ, Kolias AG, Tajsic T, Adeleye A, Aklilu AT, Apriawan T, et al: Consensus statement from the International Consensus Meeting on the Role of Decompressive Craniectomy in the Management of Traumatic Brain Injury: consensus statement. Acta Neurochir (Wien) 161:12611274, 2019

8. Leidinger A, Kim EE, Navarro-Ramirez R, Rutabasibwa N, Msuya SR, Askin G, et al: Spinal trauma in Tanzania: current management and outcomes. J Neurosurg Spine 31:103-111, 2019

9. Maas AIR, Menon DK, Adelson PD, Andelic N, Bell MJ, Belli A, et al: Traumatic brain injury: integrated approaches to improve prevention, clinical care, and research. Lancet Neurol 16:987-1048, 2017

10. Meara JG, Hagander L, Leather AJM: Surgery and global health: a Lancet Commission. Lancet 383:12-13, 2014

11. Park KB: Editorial. Research in global neurosurgery: informing the path to achieving neurosurgical equity. J Neurosurg 130:1053-1054, 2019

12. Piquer J, Qureshi MM, Young PH, Dempsey RJ: Neurosurgery Education and Development program to treat hydrocephalus and to develop neurosurgery in Africa using mobile neuroendoscopic training. J Neurosurg Pediatr 15:552-559, 2015

13. Servadei F, Rossini Z, Nicolosi F, Morselli C, Park KB: The role of neurosurgery in countries with limited facilities: facts and challenges. World Neurosurg 112:315-321, 2018

14. Servadei F, Tropeano MP, Spaggiari R, Cannizzaro D, Al Fauzi A, Bajamal AH, et al: The footprint of publications from low- and low middle income countries in the neurosurgical literature: a study from 2015 to 2017 . World Neurosurg 19:31888-31891, 2019

15. Universiti Teknologi MARA Emergency Medicine: Fellowship in Emergency Trauma Care for Emergency Physicians [brochure]. Selangor, Malaysia: UiTM (https:// emergencymedicine.uitm.edu.my/emergencwp/wp-content/ uploads/2017/11/TRAUMA-PHYSICIAN-BROCHUREUITM.pdf) [Accessed September 4, 2019]

16. Vervoort D, Park KB, Swain JD: Global cardiac surgery: lessons learnt from the global neurosurgery movement. Heart Asia 11:e011125, 2019

17. World Federation of Neurosurgical Societies: Neurosurgery by Non-neurosurgeons in Africa: Issues Involved. Vaud, Switzerland: WFNS (https://www.wfns.org/newsletter/77) [Accessed September 4, 2019]

\section{Disclosures}

The authors report no conflict of interest.

\section{Correspondence}

Franco Servadei: franco.servadei@gmail.com.

\section{INCLUDE WHEN CITING}

DOI: 10.3171/2019.8.FOCUS19682. 